\title{
Communication \\ Combination High Energy with Stability: Polynitrogen Explosives N14 and N18
}

\author{
Jifeng Chen', Yi Yu' ${ }^{2}$, Yuchuan Li1,"* and Siping Pang1,* \\ ${ }^{1}$ School of Materials Science \& Engineering, Beijing Institute of Technology, South Street No. 5, Zhongguancun, Haidian \\ District, 100081 Beijing, China; fengling1234589@126.com. \\ ${ }^{2}$ Research Institute of Aerospace Special Materials and Processing Technology, 100074, Beijing, China; ccinyuyi@163.com. \\ * Correspondence: E-mail: liyuchuan@bit.edu.cn (Y.L.); pangsp@bit.edu.cn (S.P.); Tel: +86-010-6891-5822 (Y.L.); +86-010-6891- \\ 3038 (S.P.).
}

\begin{abstract}
Novel high energy density materials N14 (1,6-dihydro-1,2,3,3a,4,5,5a,6,7,8,8a,9,10,10atetradecazapyrene) and N18 (1,2,2a,3,4,4a,5,6,6a,7,8,8a,9,10,10a,11,12a-octadecazacoronene) were designed, and their structures, detonation performance and stabilities were calculated employing density functional theory (DFT). Calculations reveals that they have a good balance between high energy and stability. Their energy gaps between LUMO and HOMO are all lower than that of TATB, while their impact sensitivity $\mathrm{h}_{50} \%$ is estimated close to that of RDX. Concerning energy, detonation performance of the N14 $(\mathrm{P}=43.6 \mathrm{GPa}, \mathrm{D}=10040 \mathrm{~m} / \mathrm{s}, \mathrm{Q}=2214$ $\mathrm{cal} / \mathrm{g})$ and the $\mathrm{N} 18(\mathrm{P}=37.4 \mathrm{GPa}, \mathrm{D}=9400 \mathrm{~m} / \mathrm{s}, \mathrm{Q}=2114 \mathrm{cal} / \mathrm{g})$ are comparable to CL-20.
\end{abstract}

Keywords: N14; N18; Density Functional Theory (DFT); High energy; Stability.

\section{Introduction}

High energy density materials (HEDMs), which possess not only perfect detonation performance but also good thermal stability and low sensitivity, have attracted considerable interests for some potential applications in propellants, explosives and pyrotechnic agents in recent years [1-5].

In order to meet main requirements in safety and power, much effort has been taken by lots of research groups [6-9]. However, in most cases, it is very difficult to concentrate both desired properties into one substance, whether traditional energetic compounds and rich nitrogen energetic salts, or polynitrogen materials.

Traditional energetic materials are developing to a bottleneck stage, so it is difficult to overcome their limits. Energetic salts offer many particular advantages over traditional energetic compounds owing to lower vapor pressures, higher heats of formation and enhanced thermal stabilities, etc [10,11]. But most of them have poorer detonation performance than excellent traditional energetic materials(HMX, RDX, CL20, etc.), such as dimethylsubstituted 5-aminotetrazolium, 3-hydeazino-4-amino-1,2,4- triazolium and other N-heterocyclic cation salts [12], or most (nitromethanidylene)-bis(1,3,4-oxadiazole-5,2-diyl)-bis(dinitromethanide) [13], 5-Nitro-3-trinitromethyl1H-1,2,4-triazolide and almost all of 5,5'-bis(trinitromethyl)-3,3'- azo-1H-1,2,4-triazole based anion salts [10].

On the other hand, polynitrogen materials have received much more attention on their high energy content due to the deviation of bond energy of $\mathrm{N}_{2}$ triple bond and $\mathrm{N}-\mathrm{N}$ single bonds or double bonds [14]. However, most of them are unstable. Since 1999, a series of $\mathrm{N}_{5}{ }^{+}$-containing salts are investigated and the most stable $\mathrm{N}_{5}{ }^{+-}$ containing salt $\mathrm{N}_{5}+\mathrm{SbF}_{6}$ is only stable at about $60^{\circ} \mathrm{C}[15,16]$. In 2004, polymeric nitrogen with cubic gauche structure was produced by Eremets [17]. Its power is five times more than that of the most powerfully energetic materials, whereas it is disappeared at ambient pressure. In 2017, two significant breakthroughs in the bulk synthesis and characterization of the pentazolate anion cyclo- $\mathrm{N}_{5-}^{-}$salts were achieved by $\mathrm{Hu}[18,19]$ and $\mathrm{Lu}[20]$, respectively. Recently, the most stable cyclo- $\mathrm{N}_{5}{ }^{-}$salt $\mathrm{Na}_{24} \mathrm{~N}_{60}$ and $\mathrm{Na}_{20} \mathrm{~N}_{60}$ occurs only below $148^{\circ} \mathrm{C}$ [21]. Besides, some other all nitrogen materials can`t exist under room temperature for a long time [14,22].

New high energy density materials are considered under the circumstances. Two novel covalent compounds, N14 and N18, are designed in this paper with the characteristics of great power and high safety, whose chemical structures are shown in Figure 1. There are 14 nitrogen atoms closely linked in N14, and 18 nitrogen atoms in N18. In these structures, that several nitrogen atoms connected directly can enhance energy. However, in most cases, high nitrogen content and stability tend to be mutually exclusive [23]. Thereby olefin and benzene ring are 
expected to form a large $\pi$ bond with nitrogen atoms to improve its stability thought the large conjugated bonds do not appear at last. A structure $\mathrm{C}_{12} \mathrm{~N}_{12}$ being similar to N18 was reported, Mondal [24] indicates that are slightly aromatic in nature, but Tursungul [25] doesn 't agree with him.<smiles></smiles>

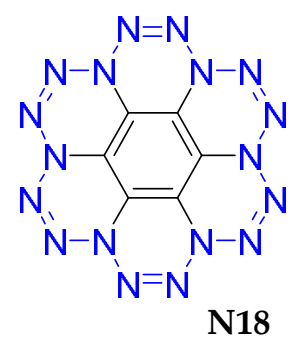

Figure 1 Chemical structure of the title compounds

Theoretical studies of N14 and N18 make it not only possible to provide forecast of properties of candidate compounds, but also possible to compare them. This paper presents the molecular geometries structures, frontier molecular orbitals, electrostatic potential (ESP), impact sensitivity $h_{50 \%}$ to illustrate their insensitivities. At the same time, the theoretical density (Q), the heat of formation (HOF), and the detonation performance is emphasized to explain their high energy. These results can also be used for comparison with property of other familiar explosives, and provide theoretical supports for molecular design of novel high energetic density compounds.

\section{Computational details}

Computations were performed with Gaussian 09 package at B3LYP level [26] method with 6-311++G (d,p) basis set. The molecular geometries and electronic structures were obtained with the density functional theory (DFT) method. The geometric parameters of these two structures were allowed to be optimized, and no constraints were imposed on molecular structures during optimization process. Structures were identified to be local minima without imaginary frequencies.

The geometric structure refers to bond length and bond angle in this paper. Bond length is one important parameter for a molecular. Commonly, the bond length is closely related with the bond stability: the longer the bond length is, the less stable the bond is [27]. Bond angle is another important parameter for a molecular and $108^{\circ}$ is an excellent value [28].

The frontier molecular orbitals include the lowest unoccupied molecular orbital (LUMO) and the highest occupied molecular orbital (HOMO). The energy gap ( $\triangle$ Ецимо-номо) is essential for kinetic stability and chemical reactivity during the chemical processes with electron transfer or leap. Previous studies have also proved that the higher energy gap, the lower chemical reactivity and vice versa [29].

Molecular electrostatic potentials (ESP) are used to describe the interaction of static electricity in molecules, and to predict chemical reactivity sites. With the help of VMD program, the very nice color-filled molecular surface maps with surface extrema can be plotted based on the output of the Multiwfn program [30]. In the map, the green and orange spheres correspond to significant minima and maxima ESP surfaces respectively. These spheres are labeled by dark blue and brown-red texts with the unit kcal $/ \mathrm{mol}$. At the same time, the global minima and maxima on the surface are labeled by larger and italic font.

Impact sensitivity is an important index to evaluate explosives, and $h_{50} \%$ is a common value to assess the index. The $\mathrm{h}_{50 \%}$ is the height where $50 \%$ probability of the "drop" result in reaction of the sample. The shorter the drop height is, the greater the impact sensitivity is. There are four methods to estimate the impact sensitivity $h_{50 \%}$ [28], shown in Equation (1) (4). Where is the difference between magnitaudes of average values of the positive and negative electrostatic potential $(\mathrm{kJ} / \mathrm{mol}), v$ is balance parameter, and $\mathrm{Q}$ is heat of detonation $(\mathrm{kJ} / \mathrm{g})$.

$$
\begin{array}{ll}
\text { Method 1: } & \left.\left.h_{50 \%}=9.2+8.03 \times 10^{2}+e^{\left[-\left(0.0875 \times \bar{V}^{+}-\mid \bar{Y}^{-}\right.\right.} \mid\right)\right] \\
\text {Method 2: } & h_{50 \%}=29.3+1.386 \times 10^{-3} \times e^{48.84 v} \\
\text { Method 3: } & \left.h_{50 \%}=27.8+0.1135 \times e^{[-(2.6477 \times[Q-6.9496)]}\right] \\
\text { Method 4: } & h_{50 \%}=1.341 \times e^{[8.1389 v-1.6234 \times(Q-6.166)]}
\end{array}
$$


The isodesmic reactions were used to predict the heat of formation (HOF) of compounds, and isodesmic reactions of N14 and N18 are shown in Scheme 1 and 2. The enthalpy of reaction $\left(\Delta_{\mathrm{r}} \mathrm{H}_{298}\right)$ at $298 \mathrm{~K}$ can be calculated according to equation (5) in the isodesmic reaction. The $\Delta_{\mathrm{f}} \mathrm{HP}_{\mathrm{P}}$ and $\Delta_{\mathrm{f}} \mathrm{H}_{\mathrm{R}}$ of following equation are the $\mathrm{HOF}$ of products and the reactants, respectively. Similarly, $\Delta \mathrm{E}_{0}, \Delta \mathrm{E} Z \mathrm{PE}_{\mathrm{H}} \Delta \mathrm{H}_{\mathrm{T}}$ are the difference between products and reactants. Furthermore, $\mathrm{E}_{0}$, EzPE and $\Delta \mathrm{H}_{\mathrm{T}}$ are total energy at $0 \mathrm{~K}$, the zero-point energy and the thermal correction from $0 \mathrm{~K}$ to $298 \mathrm{~K}$, respectively.

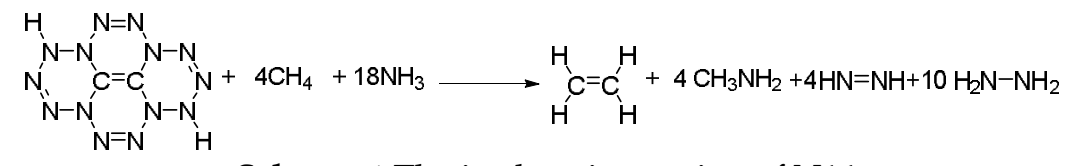

Scheme 1 The isodesmic reaction of N14

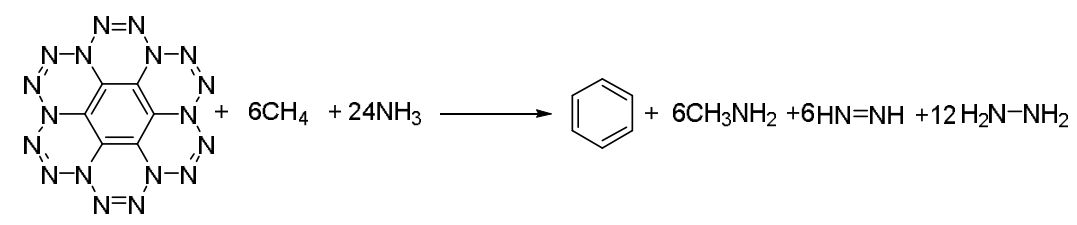

Scheme 2 The isodesmic reaction of N18

According to Equation (5), the heat of formation of the gaseous N14 and N18 $\Delta \mathrm{fH}(\mathrm{g})$ can be calculated, while the heat of formation in the condensed phase $\Delta_{\mathrm{f}} \mathrm{H}\left(\mathrm{c}\right.$ ) is determined by Equation (6). In order to estimate $\Delta \mathrm{H}_{\mathrm{sub}}$, the electrostatic potential method [31] can be used, shown in Equation (7). In the equation, $A_{s}$ and $v \sigma^{2}$ tot is derived from the molecular electrostatic potential calculation by Multiwfn software [30].

$$
\begin{gathered}
\Delta_{\mathrm{r}} H_{298}=\sum \Delta_{f} H_{P}-\sum \Delta_{f} H_{R} \\
=\Delta E_{0}+\Delta E_{Z P E}+\Delta H_{T}+\Delta n R T \\
\Delta_{f} H(c)=\Delta_{f} H(g)-\Delta H_{\text {sub }} \\
\Delta H_{\text {sub }}=0.000267\left(A_{s}\right)^{2}+1.650087\left(v \sigma_{\text {tot }}^{2}\right)^{0.5}+2.966078
\end{gathered}
$$

In the high energy density material, the crystal density (@) is an important parameter for predicting performance. Equation (8) proposed by Politzer et al [32] was used to calculate the crystal density of compounds where $\mathrm{M}$ is the molecular weight and $\mathrm{V}_{\mathrm{m}}$ is the molecular volume defined as inside a contour of 0.001 au density that was evaluated using a Monte Carlo integration. Finally, $\alpha, \beta$ and $\gamma$ here is 0.9183, 0.0028, and 0.0443, respectively.

$$
\rho=\alpha\left(\frac{M}{V_{m}}\right)+\beta\left(v \sigma_{\text {tot }}^{2}\right)+\gamma
$$

Detonation pressure $(\mathrm{P}, \mathrm{GPa})$, detonation velocity $(\mathrm{D}, \mathrm{km} / \mathrm{s})$ and heat of detonation $(\mathrm{Q}, \mathrm{cal} / \mathrm{g})$ reflecting the explosive performance of energetic materials, were estimated using EXPLO 5 (v6.01).

\section{Results and Discussion}

\subsection{Geometrical Structures}

The structure of N18 is similar to that of coronene, with periphery nitrogen atoms replacing carbon atoms. Some of periphery nitrogen atoms form double bonds while some form single bonds, and the middle carbon forms the benzene ring. We hope that the nitrogen atoms with single bond, which carry lone pair electrons, form more large conjugated system with the benzene ring and lots of azo bonds. However, the output result at B3LYP method shows that all atoms are not on coplanar, so N18 may be not an aromatic compound. The structure output of N18 is shown in Figure 2. Six carbon atoms of the benzene ring form large $\pi$ bond in the input structure, but they are linked together with double bonds in output structure. It is not corrected for keeping raw data.

In this structure, all carbon atoms are in the same plane and each C-C bond length is $1.3707 \AA$, which is shorter than that of benzene $(1.3945 \AA)$. All of the double bond nitrogen atoms are also in the same plane and the distance of N-N double bond (each one is $1.2389 \AA$ ) shorter than that of cazobenzene (1.2522 $⿱$ ). Similarly, six single bond nitrogen atoms are placed on the same plane while N-N single bond of the compound $(1.4398 \AA)$ is 
close to that of hydrazine $(1.4310 \AA)$ and C-N single bonds of the compound(1.3921 $\AA$ ) are shorter than C-NO2 of $\operatorname{TATB}(1.4366 \AA)$. The bond length of mentioned benzene, azobenzene, hydrazine and TATB is calculated using the same method with N18. In this structure, C2-C1-C3 $=120.0^{\circ}, \mathrm{N} 8-\mathrm{C} 4-\mathrm{C} 2=119.8^{\circ}, \mathrm{N} 7-\mathrm{N} 8-\mathrm{C} 4=114.2^{\circ}, \mathrm{N} 7-\mathrm{N} 8-\mathrm{N} 9$ $=109 \cdot 1^{\circ}$ and N8-N9-N10 $=121.7^{\circ}$. Because N18 has a symmetry structure, other bond angles have same value and all bond angles are approximately $108^{\circ}$. Therefore, single bond nitrogen atoms, double bond nitrogen atoms and carbon atoms are not on the same plane and form a large conjugated system, but they have special interactions to become a stable structure.
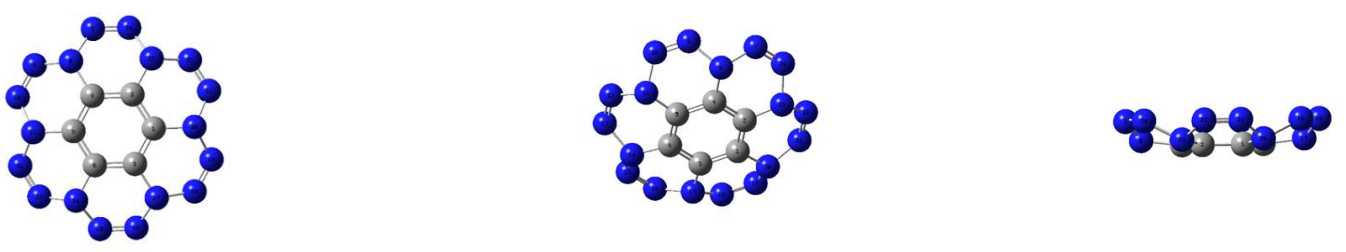

Figure 2 Structure of the N18

The structure of N14 is similar to that of pyrene, with periphery nitrogen atoms replacing carbons atoms. Moreover, it possesses two additional hydrogen atoms because nitrogen has three valence bonds. We hope that the nitrogen atoms with single bond, which carry lone pair electrons, form more large conjugated system with the C-C double bond and many azo bonds. Just like N18, the output result at B3LYP method shows that all atoms are on not coplanar, so N14 may be not an aromatic compound. The structure output of N14 is shown in Figure 3.
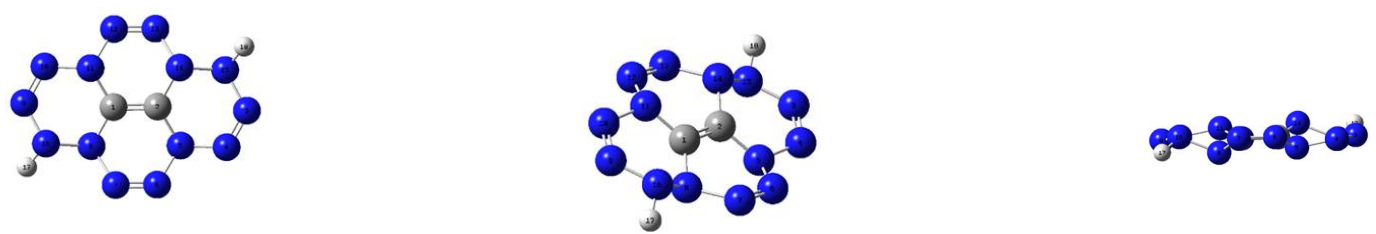

Figure 3 Structure of the N14

In the structure of N14, C-C double bond has a bond length of $1.3122 \AA$, which is shorter than that of ethylene (1.3288 $\AA$ ). The Distance of N3-N4 and N9-N10 are $1.2523 \AA$ while N6-N7 and N12-N13 are $1.2324 \AA$, and they are close to counterpart of cazobenzene. Two C-N bond lengths are 1.3922 and $1.3921 \AA$, respectively, which are shorter than C-NO2 of TATB. The N-H bond length is $1.0151 \AA$, which is closed to that of $\mathrm{NH}_{3}(1.0147 \AA)$ calculated with same method and basis set. All N-N single bond length of N14 are listed in Table 1. Some of them are shorter than that of hydrazine, and some of them are longer slightly but close to it. In the structure of N14, some bond angles are listed in Table 2 and other bond angles have same value for symmetry structure. From the table, it can be seen that all bond angles are closed to $108^{\circ}$. As the situation in N18, not all atoms in N14 are on the same plane and form a large conjugated system, but they have special interactions to become a stable structure.

Table $1 \mathrm{~N}-\mathrm{N}$ single bond length of the N14

\begin{tabular}{|c|c|c|c|}
\hline Bond & $\begin{array}{c}\text { Bond } \\
\text { length }(\AA)\end{array}$ & Bond & $\begin{array}{c}\text { Bond } \\
\text { length }(\AA)\end{array}$ \\
\hline N4-N5 & 1.3950 & N10-N11 & 1.3949 \\
\hline N9-N16 & 1.3874 & N3-N15 & 1.3873 \\
\hline N5-N6 & 1.4323 & N11-N12 & 1.4319 \\
\hline N8-N16 & 1.4634 & N14-N15 & 1.4634 \\
\hline N7-N8 & 1.4757 & N13-N14 & 1.4756 \\
\hline \multicolumn{4}{|c|}{ Table 2 Bond angles of the N14 } \\
\hline Bond & $\begin{array}{c}\text { Bond angles } \\
\left({ }^{\circ}\right)\end{array}$ & Bond & $\begin{array}{c}\text { Bond angles } \\
\left({ }^{\circ}\right)\end{array}$ \\
\hline N9-N16-N8 & 115.3 & N6-N5-N4 & 113.0 \\
\hline N16-N8-N7 & 110.4 & N5-N4-N3 & 117.8 \\
\hline N8-N7-N6 & 119.0 & N4-N3-N15 & 122.2 \\
\hline N7-N6-N5 & 119.4 & N3-N15-H18 & 106.4 \\
\hline
\end{tabular}

3.2 Frontier Molecular Orbitals 
The LUMO (a) and HOMO (b) orbits of N14 and N18 are show in Figure 4. The positive phase is red and the negative one is green. Either LUMO or HOMO doesn't locate on H atom of N14, and the two orbits locate approximately on all the atoms of N18. Energy gaps of some compounds were calculated with the same method listed in Table 3. In general, the smaller the value is, the more stable the compound is. In the table, the value of energy gap is in order HMX $\approx \mathrm{RDX}>$ FOX7 $>$ TATB. So their stability is in order TATB $>$ FOX7 $>$ RDX $\approx$ HMX, consistent with experimental values [33]. Similarly, the value of energy gap is in order TATB $>$ N14 $>$ N18, therefore their stability is in order N18 $>$ N14 $>$ TATB.

Table 3 Energy Gaps of some compounds

\begin{tabular}{llll}
\hline Compound & LUMO(au) & HOMO(au) & $\Delta \mathrm{E}(\mathrm{au})$ \\
\hline N14 & -0.10351 & -0.25456 & 0.15105 \\
N18 & -0.12522 & -0.27532 & 0.15010 \\
RDX & -0.11161 & -0.31735 & 0.20574 \\
HMX & -0.11052 & -0.32625 & 0.21573 \\
TATB & -0.12242 & -0.28092 & 0.15850 \\
FOX7 & -0.10527 & -0.27591 & 0.17064 \\
\hline
\end{tabular}

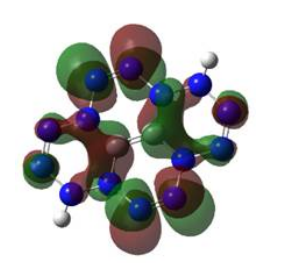

a

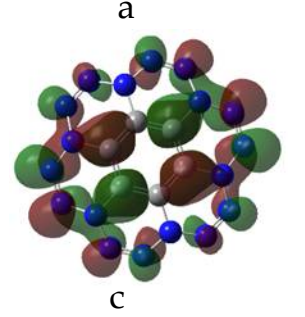

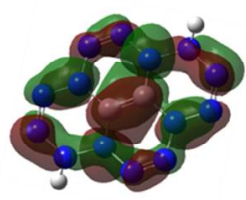

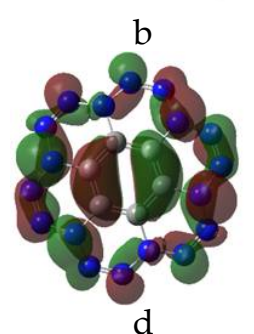

Figure 4 LUMO (a) and HOMO (b) orbitals of N14 and LUMO (c) and HOMO (d) orbitals of N18

\subsection{Electrostatic Potentials}

Electrostatic potentials map on molecular surface (a) and the surface areas in each ESP range (b) of N14 are plotted and shown in Figure 5. The surface minima of ESP is distributed near some $\mathrm{N}$ atoms due to these atoms with double bonds or lone pair electron, which are the primary electrophilic sites. The global minima site of ESP is present near the N3 atom, with the value $-24.03 \mathrm{kcal} / \mathrm{mol}$. The global maxima site of ESP is $+52.67 \mathrm{kcal} / \mathrm{mol}$, which is close to that of $\mathrm{H} 18$ atom since nitrogen atoms attracted a great deal of electrons. However, it may be not easy to be attacked by nucleophile. Because H18 with maxima in a monomer and N with surface minima in neighbor monomer product hydrogen-bond, which will result electrostatic potentials cancelled each other out. The same is to H17, other global maxima site with $+52.62 \mathrm{kcal} / \mathrm{mol}$. From Figure $5(\mathrm{~b})$, it can be seen that a large portion has a small ESP value from -25 to $+25 \mathrm{kcal} / \mathrm{mol}$. The negative part mainly corresponds to the surface above and below the several $\mathrm{N}$ atoms with the effect of the abundant lone pair electron or $\pi$-electron cloud. The biggest positive area mainly arises from C-C double bond, and the smaller ones with remarkable positive ESP value correspond to $\mathrm{C}-\mathrm{H}$ bond though that is not nucleophilic sites.

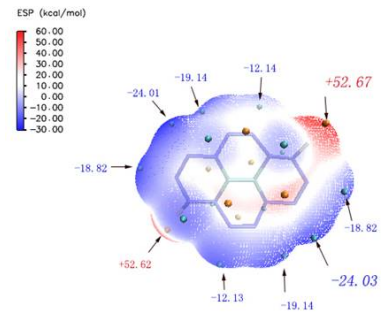

(a)

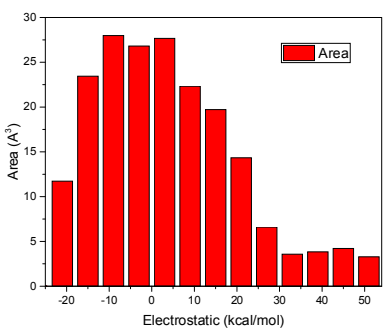

(b) 
Figure 5 Electrostatic potentials map (a) and the surface areas (b) of N14

Electrostatic potentials map on molecular surface (a) and the surface areas in each ESP range (b) of N18 is plotted and shown in Figure 6. The surface minima of ESP are distributed in the peripheral of $\mathrm{N}$ atoms ring and their values range from -17.16 to $-17.15 \mathrm{kcal} / \mathrm{mol}$ which is close to global minima. The N25 is near the global minima site, with the value $-17.16 \mathrm{kcal} / \mathrm{mol}$. Just like the minima, the surface maxima range from +42.00 to +42.14 $\mathrm{kcal} / \mathrm{mol}$, which is close to the global maxima $+42.17 \mathrm{kcal} / \mathrm{mol}$. They are located in the peripheral of benzene ring and on the same side of the global minima site. It can be seen that positive and negative potential distributed more evenly over surface. It is reported [34,35] that the more evenly the electron is distributed over the surface of the molecule, the more insensitive the molecule is. There is a large portion ESP distributing from -20 to +30 $\mathrm{kcal} / \mathrm{mol}$ as shown in Figure 6(b). Obviously, positive part arises from $\mathrm{N}$ atom and negative one comes from $\mathrm{C}$ atom.

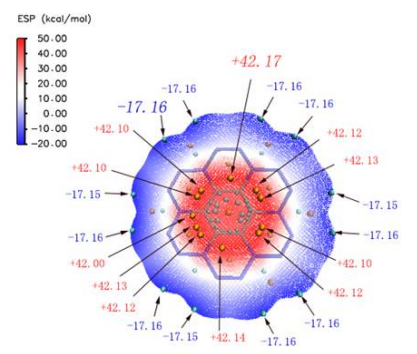

(a)

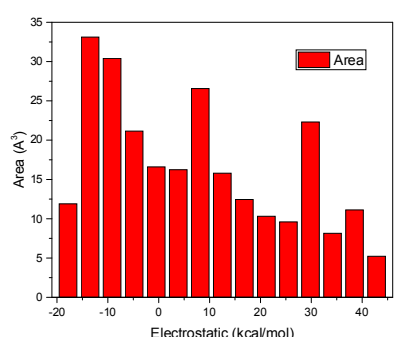

(b)

Figure 6 Electrostatic potentials map (a) and the surface areas (b) of N18

\subsection{Impact sensitivity}

The values $(\mathrm{cm})$ of $h_{50 \%}$ are estimated through four methods and the results of some compounds are summarized in Table 4. The experimental values of TNT, RDX, HMX, PETN, TATB, FOX7 and CL-20 are also shown in the table for comparison. It can be seen that values obtained from method 4 can't reflect the one of experiment, methods 1-3 show relatively consistent results. From the table the $\mathrm{h}_{50 \%}$ of title compounds may be closed to that of RDX. This result is different to the Frontier Molecular Orbitals theory because the accuracy of the predictions from the models can 't be assured entirely[36].

Table 4 Predicted and experimental $\mathrm{h}_{50 \%}$ values $(\mathrm{cm})$

\begin{tabular}{lccccc}
\hline Comp & Method1 & Method2 & Method3 & Method4 & Exp. \\
\hline TNT & 73 & 80 & 133 & 143 & 98 \\
RDX & 49 & 31 & 39 & 22 & 28 \\
HMX & 21 & 31 & 41 & 22 & 32 \\
PETN & 28 & 30 & 41 & 16 & 13 \\
TATB & 498 & 307 & 502 & 478 & 490 \\
FOX-7 & 320 & 40 & 168 & 133 & 126 \\
CL-20 & 16 & 29 & 29 & 3 & 14 \\
N14 & 114 & 32 & 28 & 0.03 & - \\
N18 & 37 & 30 & 28 & 0.04 & - \\
\hline
\end{tabular}

\subsection{Heats of Formation}

The gas phase heat of formation of N14 and N18 can be calculated according to Scheme 1, 2 and Equation (5). The experimental gas phase heat of formation of $\mathrm{NH}_{3}, \mathrm{CH}_{4}, \mathrm{C}_{6} \mathrm{H}_{6}, \mathrm{CH}_{3} \mathrm{NH}_{2}, \mathrm{~N}_{2} \mathrm{H}_{2}$ and $\mathrm{N}_{2} \mathrm{H}_{4}$ are available [37]. They are all shown in Table 5 and the gas phase heat of formation of N14 and N18 is 2142.17 and $2959.60 \mathrm{~kJ} / \mathrm{mol}$, respectively. Due to lots of nitrogen which are connected directly, their enthalpy of formation is much higher than RDX, HMX or CL-20 [38], shown in Table 8.

Table 5 Related parameters for predicting gas phase heat of formation by isodesmic reactions

\begin{tabular}{lllcc}
\hline Comp & EZPE(au) & H $_{\mathbf{T}}(\mathbf{a u})$ & E0 $\left._{\mathbf{a u}}\right)$ & $\Delta \mathbf{H}_{\mathbf{f}}(\mathbf{g})(\mathbf{k J} / \mathbf{m o l})$ \\
\hline N18 & 0.119786 & 0.016010 & -1213.869725 & 2959.60
\end{tabular}


7 of 10

\begin{tabular}{lcccc}
$\mathrm{N} 14$ & 0.101568 & 0.011946 & -843.6855212 & 2142.17 \\
$\mathrm{CH}_{4}$ & 0.044539 & 0.003813 & -40.53396275 & -74.60 \\
$\mathrm{NH}_{3}$ & 0.034252 & 0.003818 & -56.58272201 & -45.90 \\
$\mathrm{C}_{6} \mathrm{H}_{6}$ & 0.100085 & 0.005347 & -232.3113072 & 82.90 \\
$\mathrm{C}_{2} \mathrm{H}_{4}$ & 0.050775 & 0.003986 & -78.61553852 & 52.40 \\
$\mathrm{CH}_{3} \mathrm{NH}_{2}$ & 0.063782 & 0.004380 & -95.89388879 & 23.50 \\
$\mathrm{~N}_{2} \mathrm{H}_{2}$ & 0.027332 & 0.003801 & -110.6779937 & 197.07 \\
$\mathrm{~N}_{2} \mathrm{H}_{4}$ & 0.053284 & 0.004203 & -111.9106874 & 95.35 \\
\hline
\end{tabular}

The heat of formation in the condensed phase of N14 and N18 can be calculated according to Equation (6) and (7), and they are 2048.49 and $2846.46 \mathrm{~kJ} / \mathrm{mol}$, respectively. Related parameters are shown in Table 6.

Table 6 Related parameters for predicting condensed phase heat of formation

\begin{tabular}{cccccc}
\hline Comp & $\begin{array}{c}\mathbf{A}_{\mathbf{s}} \\
\left(\AA^{2}\right)\end{array}$ & $\begin{array}{c}\boldsymbol{\sigma}^{2} \text { tot } \\
\left([\mathbf{k c a l} / \mathbf{m o l}]^{2}\right)\end{array}$ & $\mathbf{v}$ & $\begin{array}{c}\mathbf{H}_{\text {sub }} \\
(\mathbf{k J} / \mathbf{m o l})\end{array}$ & $\begin{array}{c}\Delta \mathbf{H}_{\mathbf{f}}(\mathbf{c}) \\
(\mathbf{k J} / \mathbf{m o l})\end{array}$ \\
\hline N18 & 250.95424 & 170.1758509 & 0.11375910 & 113.14 & 2846.46 \\
N14 & 195.50755 & 206.0047982 & 0.15147528 & 93.68 & 2048.49 \\
\hline
\end{tabular}

\subsection{Crystal Densities}

The crystal densities of N14 and N18 can be calculated according to Equation (8), and they are 1.784 and 1.817 $\mathrm{g} / \mathrm{cm}^{3}$. Related parameters are shown in Table 7 . As these two compounds contain mainly $\mathrm{C}$ and $\mathrm{N}$, and don `t contain $\mathrm{O}$, their densities are lower than HMX and CL-20, shown in Table 8. 
Table 7 Related parameters for predicting crystal densities

\begin{tabular}{llllc}
\hline Comp & $\begin{array}{c}\mathbf{V}_{\mathbf{m}} \\
\left(\mathbf{c m}^{3} / \mathbf{m o l}\right)\end{array}$ & $\begin{array}{c}\mathbf{M} \\
\mathbf{( g / m o l})\end{array}$ & $\begin{array}{c}\mathbf{v} \sigma^{\mathbf{2}} \\
\left([\mathbf{k a l} / \mathbf{m o l}]^{\mathbf{2}}\right)\end{array}$ & $\begin{array}{c}\mathbf{Q} \text { cry } \\
\mathbf{( g / \mathbf { c m } ^ { 3 } )}\end{array}$ \\
\hline N18 & 173.12408 & 324 & 19.3590517 & 1.82 \\
N14 & 122.81914 & 221 & 31.2046336 & 1.78 \\
\hline
\end{tabular}

\subsection{Detonation Performance}

The detonation velocity (D), detonation pressure $(\mathrm{P})$ and heat of detonation (Q) of N14 and N18 are computed based on their crystal densities $(\mathrm{Q})$ and condensed phase heats of formation $\Delta_{\mathrm{f}} \mathrm{H}(\mathrm{c})$. Their detonation performance, including RDX, HMX and CL-20 [39] are shown in Table 8. It reveals that detonation performance of the N14 (Q = $2214 \mathrm{cal} / \mathrm{g}$ and $\mathrm{D}=10040 \mathrm{~m} / \mathrm{s})$ and $\mathrm{N} 18(\mathrm{Q}=2114 \mathrm{cal} / \mathrm{g}$ and $\mathrm{D}=9400 \mathrm{~m} / \mathrm{s})$ are higher than that of CL-20 while their detonation pressures (43.6 GPa and 37.4 GPa) are lower.

Table 8 Detonation performance of HEDM

\begin{tabular}{|c|c|c|c|c|c|}
\hline Comp & $\begin{array}{c}\mathrm{Q} \\
\left(\mathrm{g} / \mathrm{cm}^{3}\right)\end{array}$ & $\begin{array}{l}\Delta_{\mathrm{fH}}(\mathrm{c}) \\
(\mathrm{kJ} / \mathrm{mol})\end{array}$ & $\begin{array}{c}\mathrm{Q} \\
\text { (cal/g) }\end{array}$ & $\begin{array}{c}D \\
(\mathrm{~m} / \mathrm{s})\end{array}$ & $\begin{array}{c}P \\
(\mathrm{GPa})\end{array}$ \\
\hline N18 & 1.82 & 2846.46 & 2114 & 9400 & 37.4 \\
\hline N14 & 1.78 & 2048.49 & 2214 & 10040 & 43.6 \\
\hline $\mathrm{RDX}^{\mathrm{a}}$ & 1.80 & 79.00 & 1501 & 8750 & 34.7 \\
\hline $\mathrm{HMX}^{\mathrm{a}}$ & 1.90 & 102.41 & 1498 & 9100 & 39.3 \\
\hline$\varepsilon-C L-20^{a}$ & 2.04 & 377.04 & 1567 & 9380 & 44.1 \\
\hline
\end{tabular}

a The detonation performance values are computational data from reference [39].4. Conclusions

In this work, N14 and N18 are calculated by Gaussian 09 package at B3LYP method with 6-311++G (d, p) basis set to investigate their detonation performance and stability. The results show that detonation performance of N14 (P = 43.6 GPa, D =10040 m/s, Q = $2214 \mathrm{cal} / \mathrm{g})$ and N18 (P = $37.4 \mathrm{GPa}, \mathrm{D}=9400 \mathrm{~m} / \mathrm{s}, \mathrm{Q}=2114 \mathrm{cal} / \mathrm{g})$ are comparable to the value of CL-20. What's more, their energy gaps ( $\triangle$ ELUMO-HOMO) are superior to TATB`s and their impact sensitivity $\mathrm{h}_{50}$ may be close to RDX. Considering both the detonation properties and stabilities, they are all likely to be used as candidates of high energy density materials with low sensitivity and high performance, and these results can also be used for comparison with property of other familiar explosives, and provide theoretical supports for molecular design of novel high energetic density compounds. Further work on route optimization and practical synthesis is being carried out by our team.

\section{Acknowledgements}

This work was supported by the National Natural Science Foundation of China (NO.21576026).

\section{References}

1. Zeng, Q.; Qu, Y.; Li, J.; Huang, H. Theoretical studies on the derivatives of tris([1,2,4]triazolo)[4,3-a:4' ${ }^{\prime} 3^{\prime}$ c:4' ' , 3' ' -e][1,3,5]triazine as high energetic compounds. RSC Adv 2016, 6, 5419-5427.

2. Chen, J.; Yu, Y.; Li, Y.; Pang, S. Reagents leading to difluoramino (NF2 ) products. J Fluorine Chem 2018, 205, 35-42.

3. Yu, Y.; Chen, J.; Zhang, R.; Li, Y.; Pang, S. Novel [NF2O]+ and [N3NFO]+-based energetic oxidizers for solid propellants with super high specific impulse. RSC Adv 2017, 7, 23709-23713.

4. Qi, C.; Zhang, R.B.; Zhang, X.J.; Li, Y.C.; Wang, Y.; Pang, S.P. Theoretical investigation of 4,4',6,6'tetra(azido)azo-1,3,5-triazine-n-oxides and the effects of $\mathrm{n}-->\mathrm{o}$ bonding on organic azides. Chem Asian $\mathrm{J}$ 2011, 6, 1456-1462.

5. Yin, P.; Mitchell, L.A.; Parrish, D.A.; Shreeve, J.M. Comparative study of various pyrazole-based anions: A promising family of ionic derivatives as insensitive energetic materials. Chem Asian J 2017, 12, 378-384.

6. Tang, Y.; Kumar, D.; Shreeve, J.M. Balancing excellent performance and high thermal stability in a dinitropyrazole fused 1,2,3,4-tetrazine. J Am Chem Soc 2017, 139, 13684-13687.

7. Meng, L.; Lu, Z.; Wei, X.; Xue, X.; Ma, Y.; Zeng, Q.; Fan, G.; Nie, F.; Zhang, C. Two-sided effects of strong hydrogen bonding on the stability of dihydroxylammonium 5,5' -bistetrazole-1,1' -diolate (tkx-50). Cryst Eng Comm 2016, 18, 2258-2267.

8. Huang, S.; Tian, J.; Qi, X.; Wang, K.; Zhang, Q. Synthesis of gem-dinitromethylated and 
fluorodinitromethylated derivatives of 5,5'-dinitro-bis-1,2,4-triazole as promising high-energy-density materials. Chem Eur J 2017, 23, 12787-12794.

9. Cui, K.; Meng, Z.; Xu, Z.; Xue, M.; Lin, Z.; Wang, B.; Ge, Z.; Qin, G. Characterization of hydrazinium 3,5dinitroamine-1,2,4-triazole. J Energ Mater 2014, 32, S60-S70.

10. Thottempudi, V.; Shreeve, J.M. Synthesis and promising properties of a new family of high-density energetic salts of 5-nitro-3-trinitromethyl-1h-1,2,4-triazole and 5,5'-bis(trinitromethyl)-3,3'-azo-1h-1,2,4-triazole. J Am Chem Soc 2011, 133, 19982-19992.

11. Singh, R.P.; Verma, R.D.; Meshri, D.T.; Shreeve, J.M. Energetic nitrogen-rich salts and ionic liquids. Angew Chem Int Ed Engl 2006, 45, 3584-3601.

12. Liu, W.; Liu, W.L.; Pang, S.P. Structures and properties of energetic cations in energetic salts. RSC Adv 2017, 7, 3617-3627.

13. Yu, Q.; Imler, G.H.; Parrish, D.A.; Shreeve, J.M. Nitromethane bridged bis(1,3,4-oxadiazoles): Trianionic energetic salts with low sensitivities. Chem Eur J 2017, 23, 17682-17686.

14. Christe, K.O.; Wilson, W.W.; Sheehy, J.A.; Boatz, J.A. N5+: A novel homoleptic polynitrogen ion as a high energy density material. Angew Chem Intl Edit 2001, 40, 2947-2947.

15. Christe, K.O. Recent advances in the chemistry of N5+, N5- and high-oxygen compounds. Propell, Explos, Pyrot 2007, 32, 194-204.

16. Wang, F.; Du, H.; Zhang, J.; Gong, X. Dft studies on the structures and stabilities of N5+-containing salts. Struct Chem 2011, 22, 1067-1073.

17. Eremets, M.I.; Gavriliuk, A.G.; Trojan, I.A.; Dzivenko, D.A.; Boehler, R. Single-bonded cubic form of nitrogen. Nat Mater 2004, 3, 558-563.

18. Zhang, C.; Sun, C.; Hu, B.; Yu, C.; Lu, M. Synthesis and characterization of the pentazolate anion cyclo-N5- in (N5)6(H3O)3(NH4)4Cl. Science 2017, 355, 374-376.

19. Zhang, C.; Yang, C.; Hu, B.; Yu, C.; Zheng, Z.; Sun, C. A symmetric Co(N5 )2 (H2O)4 •4H2O high-nitrogen compound formed by cobalt(ii) cation trapping of a cyclo-N5(-) anion. Angew Chem Intl Edit 2017, 56, 45124514.

20. Xu, Y.; Wang, Q.; Shen, C.; Lin, Q.; Wang, P.; Lu, M. A series of energetic metal pentazolate hydrates. Nature 2017, 549, 78-81.

21. Zhang, W.; Wang, K.; Li, J.; Lin, Z.; Song, S.; Huang, S.; Liu, Y.; Nie, F.; Zhang, Q. Stabilization of the pentazolate anion in a zeolitic architecture with Na20N60 and Na24N60 nanocages. Angew Chem Intl Edit 2018, 57, 2592-2595.

22. Strout, D.L. Acyclic n10 fails as a high energy density material. J Phys Chem A 2002, 106, 816-818.

23. Zhang, Q.; Shreeve, J.M. Growing catenated nitrogen atom chains. Angew Chem Intl Edit 2013, 52, 8792-8794.

24. Mondal, S.; Srinivasu, K.; Ghosh, S.K.; Chattaraj, P.K. Isomers of C12N12 as potential hydrogen storage materials and the effect of the electric field therein. RSC Adv 2013, 3, 6991.

25. Tawar, T.; Kerim, A. A study of the aromaticity of the heterofullerene C24-2nBnNn ( $\mathrm{n}=3$ or 6 ) and C12N12 isomers. Fuller Nanotub Car N 2015, 23, 846-852.

26. Frisch, M.J.; Trucks, G.W.; Schlegel, H.B.; Scuseria, G.E.; Robb, M.A.; Cheeseman, J.; Scalmani, G.; Barone, V.; Mennucci, B.; Petersson, G.A., et al. Gaussian 09 revision a.1. Gaussian inc. 2009.

27. Jin, X.; Zhou, J.; Wang, S.; Hu, B. Computational study on structure and properties of new energetic material 3,7-bis(dinitromethylene)-2,4,6,8-tetranitro-2,4,6,8-tetraaza-bicyclo[3.3.0]octane. Quím Nova 2016, 39, 467-473.

28. He, P.; Zhang, J.-G.; Wu, L.; Wu, J.-T.; Zhang, T.-L. Computational design and screening of promising energetic materials: Novel azobis(tetrazoles) with ten catenated nitrogen atoms chain. J Phys Org Chem 2017, 30, e3674.

29. Li, Y.-F.; Fan, X.-W.; Wang, Z.-Y.; Ju, X.-H. A density functional study of substituted pyrazole derivatives. J Mol Struct 2009, 896,96-102.

30. Lu, T.; Chen, F. Multiwfn: A multifunctional wavefunction analyzer. J Comput Chem 2012, 33, 580-592.

31. Byrd, E.F.C.; Rice, B.M. Improved prediction of heats of formation of energetic materials using quantum mechanical calculations. J Phys Chem A 2006, 110, 1005-1013.

32. Politzer, P.; Martinez, J.; Murray, J.S.; Concha, M.C.; Toro-Labbé, A. An electrostatic interaction correction for improved crystal density prediction. Mol Phys 2009, 107, 2095-2101.

33. Talawar, M.B.; Sivabalan, R.; Mukundan, T.; Muthurajan, H.; Sikder, A.K.; Gandhe, B.R.; Rao, A.S. 
10 of 10

Environmentally compatible next generation green energetic materials (gems). J Hazard Mater 2009, 161, 589607.

34. Zhao, X.; Zhang, S.; Li, S.; Lu, J.; Zhang, J.; Pang, S. Searching for long intra-annular nitrogen chains: Synthesis, characterization, and decomposition mechanism of tetrazolo[1,5-b][1,2,4]triazines. Mater Design 2016, 90, 1050-1058.

35. Hammerl, A.; Klapötke, T.M.; Nöth, H.; Warchhold, M.; Holl, G. Synthesis, structure, molecular orbital and valence bond calculations for tetrazole azide, CHN7. Propell, Explos, Pyrot 2003, 28, 165-173.

36. He, P.; Zhang, J.G.; Wang, K.; Yin, X.; Zhang, T.L. Combination multinitrogen with good oxygen balance: Molecule and synthesis design of polynitro-substituted tetrazolotriazine-based energetic compounds. J Org Chem 2015, 80, 5643-5651.

37. Cox, J.D. Methods for measurement or estimation of thermodynamic properties of chemical substances in use in division of chemical standards npl. Transactions of the Institution of Chemical Engineers and the Chemical Engineer 1967, 45, 1-57.

38. Qi, C.; Li, S.H.; Li, Y.C.; Wang, Y.; Zhao, X.X.; Pang, S.P. Synthesis and promising properties of a new family of high-nitrogen compounds: Polyazido- and polyamino-substituted N,N'-azo-1,2,4-triazoles. Chem Eur J 2012, 18, 16562-16570.

39. Politzer, P.; Murray, J.S. Some perspectives on estimating detonation properties of C, H, N, O compounds. Cent Eur J Energ Mat 2011, 8, 209-220. 